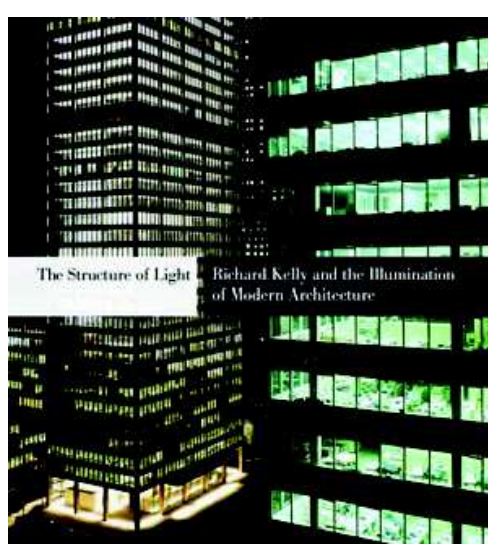

The STRUCTURE OF Light: RICHARD KELLY AND THE ILLUMINATION OF MODERN ARCHITECTURE

NEUMANN, DiETRICH; STERN, Robert A. M. Nova York: Yale University Press, 20io. 2 I4 P.

ISBN: 978-0-300-I6370-4

Fernanda Brito Bandeira

Paulo Sergio Scarazzato

\title{
RICHARD KELLY: PIONEIRISMO NA ILUMINAÇÃO DA ARQUiTETURA MODERNA
}

No ano do centenário de nascimento de Richard Kelly (2010), a Yale School of Architecture organizou exposição e publicou um livro em homenagem àquele grande pioneiro do "lighting design" que teve a oportunidade de iluminar obras dos mais importantes arquitetos modernistas de seu tempo, naturais ou estabelecidos nos EUA, entre eles Mies van der Rohe, Louis Khan e Philip Johnson, que o chamava de "homem da luz". O livro, intitulado A Estrutura da Luz. Richard Kelly e a iluminação da Arquitetura Moderna, de rara beleza e ricamente ilustrado, possibilita ao leitor mergulhar no fantástico universo da genialidade de Kelly.

Tanto a exposição quanto a publicação do livro só se tornaram possíveis graças à doação de documentos à biblioteca da universidade de Yale por Addison Kelly, filha de Kelly. Foram 765 arquivos de projetos em 92 caixas, 145 rolos de desenhos e outras 25 caixas com agendas ricas em informações pessoais e profissionais, e notas meticulosas que se constituem em verdadeiro diário entre 1948 e 1977, ano de sua morte. Desde o início de carreira, Kelly valorizou o registro de suas ideias e conceitos, estes representados por inúmeros ensaios. A organização do texto e o cuidado na seleção das ilustrações permitem ao leitor familiarizar-se com a vida e a obra Kelly, um arquiteto que, em meados da década de 1930 ousou, ao inaugurar um novo campo de atuação profissional até então inexistente.

A publicação equilibra de modo sutil o retrato de uma época, com ênfase ao surgimento do "lighting design" e seu papel na valorização da arquitetura moderna. Por esta razão deve cativar o leitor brasileiro pela afinidade deste com aquele movimento, tão significativo a partir dos legados de Oscar Niemeyer, Lúcio Costa, MMM Roberto, Affonso Eduardo Reidy e outros.

Grata surpresa para alguns, ou muitos, é a revelação de que Kelly também marcou presença no Brasil em meados da década de 1960, quando foi 
contratado pelo governo do então Estado da Guanabara, para desenvolver projetos de iluminação para o Pão de Açúcar, o Cristo Redentor e o Parque do Flamengo, à época na fase de implantação. Para a iluminação daquele que viria a ser o maior parque urbano do mundo, ele projetou postes com mais de $45 \mathrm{~m}$ de altura, com luminárias providas de lâmpadas de descarga em alta intensidade que produziam uma luz extremamente branca e brilhante, uma novidade à época. Sua intenção era mimetizar a luz da lua nas noites tropicais, o que foi alcançado com maestria e muita sensibilidade. Ainda hoje, mais de cinquenta anos depois, os grandes postes ainda se destacam na paisagem

$\mathrm{O}$ pioneirismo de Kelly se revelou também no campo conceitual. Seu entendimento acerca da iluminação como uma realidade tridimensional se traduziu em tríade decorrente do que ele aprendeu com o teatro quando ainda cursava arquitetura na Columbia University, tempo em que, além de assíduo frequentador da Broadway - fascinado mais pela iluminação do que pelos próprios espetáculos - ingressou no grupo de teatro de sua universidade, onde atuou tanto como diretor como iluminador. No seu entender, a iluminação poderia se apresentar como "foco fulgurante", efeito resultante do canhão de luz do teatro contemporâneo, "luminescência ambiente", representada pela luz do ciclorama e "jogo de cintilações", que pode ser interpretado como a Broadway à noite, com sua iluminação feérica. A aqueles conceitos, ele atribuiu seis importantes qualidades: intensidade, brilho, difusão, luminosidade espectral, direção e movimento. E, em uma revisão posterior, incluiu questões de iluminação natural, e seu possível diálogo com a iluminação artificial. Assim, por exemplo, "foco fulgurante" pode ser a luz da janela sobre uma cadeira de leitura preferida, ou um foco de luz de uma iluminação de tarefa. A "luminescência ambiente" pode ser representada pela parede desnuda de uma galeria de arte, ou um teto translúcido. E, como "jogo de cintilações", a luz do sol refletida nas águas que se movem em um riacho.

Kelly soube aproveitar o momento próspero vivido pelos EUA, depois da Grande Depressão e a crescente aceitação da arquitetura moderna no país, com a qual ele se identificava. Competência, sensibilidade e pleno conhecimento dos avanços tecnológicos de seu tempo, tornaram seu nome indissociável da história da tecnologia da iluminação, entre as décadas de 1930 e 1970.

O livro, organizado por Dietrich Neumann e que contou com a participação de outros cinco colaboradores, das áreas acadêmica e profissional, inclui a relação de 125 projetos mais importantes de Kelly, segundo seleção feita por ele mesmo nos anos 1970. A obra, composta por seis seções, brinda o leitor com mais de 200 imagens, e com o catálogo da exposição.

A primeira das seções, "Theater, Lights and Architecture: The Career of Richard Kelly", é autoria de Dietrich Neumann. Ela apresenta Kelly e sua carreira, e pessoas que o influenciaram. E afirma que muitos dos avanços daquele período resultaram seus experimentos relativos à iluminação de sets de filmagem ou montagens de peças da Broadway. Não por acaso, a dramatização é uma das ferramentas dos lighting designers.

A segunda, terceira e quarta seção - "The Invention of Modern Light: Richard Kelly and Home Lighting", "Corporate America and the New Luminous Environment: Kelly's Work with Johson, Mies and Noyes", e "Light Changes: Philip Johson, Richard Kelly, and Stimmung at Seagram", respectivamente referem-se a grandes nomes da arquitetura norte-americana da época, cujas 
obras foram iluminadas por Kelly, e possibilitam conhecer melhor duas das tipologias mais importantes para a carreira de Kelly: a residencial e a corporativa.

Em "Evolving Technology, Devolving Lighting", na quinta parte, D. Michelle Addington, apresenta os avanços tecnológicos que deram suporte ao trabalho de Kelly.

Guardada para o final, a seção "Two Skylights", escrita por Matthew Tanteri apresenta o preciosismo de Kelly nos projetos de iluminação natural para os museus Kimbell Art em Fort Worth, Texas (1966 - 1972) e o Yale Center for British Art, em New Haven, Connecticut (1969 - 1974), ambos projetados por Louis Kahn. Naquelas obras, Kelly aplicou com maestria qualidades da luz pregadas por ele próprio: intensidade, brilho, difusão, luminosidade espectral, direção e movimento, sendo que a luz difusa é a que mais se destaca. São obras que atestam sua genialidade.

\section{Nota do Autor}

Financiamento: Fapesp (Processo 2017/05309-0).

\section{Nota do Editor}

Revisão: Prof. ${ }^{a}$ Fabíola Negrão Baldani, MEC 009041

\section{Fernanda Brito Bandeira}

Faculdade de Engenharia Civil, Arquitetura e Urbanismo. Universidade Estadual de Campinas. Campinas, SP.

fbritobandeira@gmail.com

\section{Paulo Sergio Scarazzato}

Faculdade de Engenharia Civil, Arquitetura e Urbanismo. Universidade Estadual de Campinas. Campinas, SP.

Faculdade de Arquitetura e Urbanismo. Universidade de São Paulo. São Paulo, SP. pasezato@usp.br, paulosca@fec.unicamp.br 